\title{
MORBIDITY PATTERN IN HEALTH CARE PROVIDERS IN SINDH
}

\author{
Hussain Bux Kolachi, Ayoob Ali and Mansoor A. Khuwaja
}

\begin{abstract}
OBJECTIVE: To know current morbidity pattern in health care providers serving in Heath Department of Sindh, Pakistan.

DESIGN: This study was conducted during years 2001-2004.

METHODS: Study was conducted through Health Management Information System (HMIS) Cell Directorate General of Health Sindh based at Hyderabad and Faculty of Community Medicine Liaquat University of Medical and Health Sciences, Jamshoro - Sindh. Questionnaires were distributed to doctors who were selected for HMIS course and were providing health care services in various first level health care facilities and referral level care facilities. Health care providers belonged to 15 districts of Sindh where HMIS trainings were held and these were included in this study. Total 169 medical officers participated and filled the proforma.

RESULTS: Out of 169 health care providers studied, 143 were males and 26 females. Majority i.e. 29(17.15\%) male doctors and only 2 female doctors reported that they have some kind of morbidity currently. Their morbidity patterns included cardiovascular diseases, gastro-intestinal diseases and other non-communicable diseases. Allergic diseases, physical disabilities and injuries were also reported by them.

CONCLUSION: This study found that $17.1 \%$ of health care providers or (171 per 1000 doctors population) is suffering from some form of morbidity which is higher than morbidity pattern in general population which is about $15 \%$ or (150 per 1000 population.) as reported in national health statistics. This situation is worrying for health care providers and needs special attention for preventive care.
\end{abstract}

KEY WORDS: Morbidity. Health. Health Care Providers. Population.

\section{INTRODUCTION}

The care providers are backbone of any health delivery system. Without their technical and administrative inputs, health delivery system can not function smoothly. Sindh is second largest province of Pakistan with population of over 30 millions. ${ }^{1}$ The Health Department of Government of Sindh is major health care provider in province having 1200 first level health care facilities (FLCFs) and referral level care facilities (RLCFs) staffed by around 8000 male and female doctors posted as Medical Officers (MOs) and Woman Medical Officers (WMOs). There is no system of health screening for working physicians. Their health status is assessed once at the time of appointment and fitness certificates are issued. ${ }^{2} \mathrm{~A}$ study done to know the health status of 150 female physicians who were asked about their health condition's perception by Unaiza, et al in Karachi during 2003 revealed that $71 \%$ of the women physicians perceived their physical health as good, while $34 \%$ of women physicians did not feel their health good and felt high levels of stress. ${ }^{3}$ Most of studies in United Kingdom (UK) and
Australia related to health status have also discovered that doctors pay little attention to their own health conditions. In United Kingdom where health system is well developed, a recent study of 408 General Practitioners (GPs) reported that 50\% GPs have serious illnesses or gone through surgical operations. ${ }^{4}$ Their illnesses were similar to general population. It was alarming that $8.6 \%$ doctors retired before age of sixty years on ground of sickness. ${ }^{4,5}$ Doctors are more vulnerable to depression as well as suicide due to stress of job. Doctors dying chances are also higher from physical diseases than mental illnesses. .,7,8 $^{-1}$ Common illnesses which are responsible for morbidity in Pakistan in general population are fairly welldefined. Most of these conditions are attributable to under nutrition, anemia, unclean water supply and sanitation, ignorance, high fertility and poverty. While some factors may be perceived by doctors as outside the field of medicine. In a study of the elderly conducted in Karachi revealed common problems like hypertension in $52 \%$ elderly people while diabetes $(16 \%)$, difficulty in walking (47\%), visual impairment (71\%) and hearing loss were also reported. One-third 
of hypertensive patients could not purchase the drugs which they need for life long period. ${ }^{8-10}$ Nation-wide survey in 1982-83 in Pakistan, first time pointed out the burden of disease in the society. About one-sixth of the population suffered from an illness during the past one month period. Over two-thirds of those who fell ill, suffered from malaria and fever and one-fifth from diarrhoea and dysenteries. The cost of health care on an average was $4 \%$ of the total income of family in the urban and $5 \%$ in the rural areas. Therefore, it was suggested that broad based national health policy and implementation of primary health care programme will alter this poor health situation of the nation. ${ }^{11}$ It has also been found in different surveys that there is non-availability of basic and essential health care needed by rural population. The possible reasons can be attributed to lack of health infrastructure and low literacy, inadequate funding and planning and shortage of health force deployment and lack of social support and machinery. ${ }^{12}$ The health of a nation depends not simply on the provision of doctors, hospitals and sophisticated equipments. It depends on the existence of basic health concepts, not only in the minds of individuals but also in the mind of those who frame policies and enjoy the power of implementation. It is regrettable that while we are opening new hospitals and introducing state of the art technology, and human expertise, but doing nothing about the deteriorating public health services in Pakistan. So much so, that people have in fact forgotten what public health means and what is the scope of public health interventions in the overall well being of the society. ${ }^{13}$ This study was designed to explore the health problems of the doctors working in health department of Sindh who are the major health force to deliver health services to the community. As if they are themselves sick, then their quality of services will be reduced and efficiency of the health delivery system will also be unsatisfactory which will result in under utilization of services. This study is important for doctors to sensitize them for improvement of their health and health of the community. Objective of this study was to determine the morbidity pattern in health care providers (Doctors) employed in Sindh Health Department and to suggest appropriate recommendations to reduce morbidity prevalence among doctors of Sindh.

\section{SUBJECTS AND METHODS}

This descriptive cross sectional study was conducted through Health Management Information System (HMIS) Cell Directorate General of Health Sindh Hy- derabad and Faculty of Community Medicine and Public Health Sciences, Liaquat University of Medical and Health Sciences Jamshoro Sindh - Pakistan during years 2001-2004. Medical officers working in rural or urban areas (BHUs, RHCs, THQs and DHQs) in 15 districts of government run FLCFs and RLCFs in Sindh were enrolled for study. A questionnaire was formulated and pre-tested to collect data from these health care providers. Study variables included personal data, health problems, their treatment and the cost of treatment. Total 224 questionnaires were sent to health care providers. Out of these, 169 were filled and returned by them. Data was analyzed on SPSS version 10.0. Doctors working in the government health facilities and nominated in HMIS training and whose names were present in the training list were included in the study. Out of total 21 districts of Sindh at that time, 15 districts where HMIS training was conducted were included in the study. The GPs and doctors not nominated in HMIS training were excluded from the study.

\section{RESULTS}

For this study, total 220 questionnaires were mailed to participants. Out of these, 169 questionnaires were filled up and returned, giving response rate of $74.44 \%$. Of 169 filled responses, 143(84.61\%) were filled by male doctors and $26(15.38 \%)$ by female doctors. The age distribution of these health care providers showed that $11(6.70 \%)$ doctors were in $25-29$ years of age and $20(11.83 \%)$ in $30-34$ years age group. While 53 $(31.36 \%)$ were in the age group of 35-39 years. The highest number i.e. 65(38.36\%) was in age group of 40-44 years, 15 (8.87\%) in age group 45-49 and 5 $(2.95 \%)$ in age group 50 and above years. Regarding marital status, out of 169 doctors, 123 males and 15 females i.e. $138(81.65 \%)$ were married while 20 males and 11 females ( $n=31,18.35 \%)$ were unmarried. Among 169 participants, 29 doctors (17.15\%) reported that they were currently suffering from sickness/morbidity including 2 female doctors while 140 (82.85\%) said they have no sickness which included 116 male doctors and 24 females doctors. Morbidities reported by 29 doctors showed that cardiovascular diseases were present in $12(41.37 \%)$ doctors, gastrointestinal diseases in 6(20.87\%), other non- communicable diseases in 10 (34.48\%) and communicable diseases in $1(3.44 \%)$ case. Details about these diseases are presented in Table I. In this way, morbidity rate of doctors in Sindh was 171.15 per 1000 doctors. 
Hussain Bux Kolachi, Ayoob Ali and Mansoor A. Khuwaja

TABLE I: MORBIDITY PATTERN REPORTED BY HEALTH CARE PROVIDERS $(n=29)$

\begin{tabular}{|l|ll|lc|lc|}
\hline \multicolumn{1}{|c|}{ Morbidity } & \multicolumn{3}{c|}{ Male } & \multicolumn{2}{c|}{ Female } & \multicolumn{2}{c|}{ Total } \\
\hline Hypertension & 09 & 31.03 & 01 & 3.44 & 10 & 34.48 \\
\hline Heart disease & 01 & 3.44 & 00 & 00 & 01 & 3.44 \\
\hline Myocardial infarction & 01 & 3.44 & 00 & 00 & 01 & 3.44 \\
\hline Hepatitis & 01 & 3.44 & 00 & 00 & 01 & 3.44 \\
\hline Diabetes mellitus & 02 & 6.89 & 01 & 3.44 & 03 & 10.34 \\
\hline Peptic ulcer & 01 & 3.44 & 00 & 00 & 01 & 3.44 \\
\hline Hernia & 01 & 3.44 & 00 & 00 & 01 & 3.44 \\
\hline Lipoma & 01 & 3.44 & 00 & 00 & 01 & 3.44 \\
\hline Allergic disease/Asthma & 03 & 10.34 & 00 & 00 & 03 & 10.34 \\
\hline Headache & 02 & & 00 & 00 & 02 & 6.89 \\
\hline Bone and joint disorders & 01 & 3.44 & 00 & 00 & 01 & 3.44 \\
\hline Vision disorders & 02 & 6.89 & 00 & 00 & 02 & 6.89 \\
\hline Disability/injury & 01 & 3.44 & 00 & 00 & 01 & 3.44 \\
\hline Total & $\mathbf{2 7}$ & $\mathbf{9 3 . 1 0}$ & $\mathbf{0 2}$ & $\mathbf{6 . 8 9}$ & $\mathbf{2 9}$ & $\mathbf{1 0 0}$ \\
\hline
\end{tabular}

\section{DISCUSSION}

Studies in United Kingdom, Australia and New Zealand show that the doctors health is major area of concern and reported morbidity among doctors ranging from $44 \%$ to $50 \%$. ${ }^{1,6}$ This study also shows that the health status of physicians / doctors in Sindh is not satisfactory as $17.15 \%$ of our health care providers were sick at the time of study. Findings of this study are also similar to an extent to a study done on 150 female physicians practicing in Karachi, Pakistan during 2003 which found $29 \%$ physicians with some illness. ${ }^{3,7}$ The low prevalence of diseases in rural Sindh doctors, as found in our study may be due to the reason that these health care providers consider only some major illness as a health problem while doctors in developed countries as well as in Karachi consider minor problems as health morbidities and this perception has possibly given low figures in this study than similar studies reported above. ${ }^{1,2,3}$ The nation wide survey done in 1982-83 and reported in $1993-1994$ by Karim MS reported the morbidity of 150 per 1000 population or (15\%) in Sindh, Pakistan. While national morbidity figure was 171 per 1000 population or $17 \%$ in Pakistan. The morbidity found in our study is $2 \%$ higher when compared with figures of Sindh province, while it is equal to national morbidity figures. ${ }^{11}$ This study found cardiovascular/hypertension sickness in $34 \%$ subjects while the cardiovascular disease in UK is reported as $4 \%-15 \%$. In this way, this is alarming situation that our doctors are twice suffering from cardiovascular / hypertension problems than their UK counterparts ${ }^{1}$ The hypertension in elderly population of Karachi is also reported as $52 \%{ }^{4-6}$ The similarity in this study and other studies was that no doctor reported sexually transmitted diseases (STDs). This shows that doctors are perhaps shy to report STDs. Most of their problems included non-communicable chronic and life long morbidities, but, amazingly no female doctor mentioned gynecological or obstetric problem perhaps, due to privacy and shyness reasons. Out of 26 female doctors, only 2 mentioned that they are sick. Perhaps, they did not want to expose their health problems to others because of possible cultural and personal reasons. The UK GPs have reported cancer in $2 \%-3 \%$, but no our health care provider reported this problem. Western doctors have reported suffering from respiratory diseases upto $21 \%$ while our doctors did not report this problem. However, $10 \%$ participants reported allergic disorder including asthma mostly due to environmental pollution and deteriorating hygienic conditions. Vision problem was more reported by our doctors in whom $6.9 \%$ had this disorder but it is reported uncommon in other studies. ${ }^{10-13}$

\section{CONCLUSION AND SUGGESTIONS}

This study concludes that morbidity rate among doc- 
tors working in Sindh Health department is 171 per 1000 -doctor population or $17 \%$ in doctors which is $2 \%$ higher than the provincial general population morbidity rate but equal to national morbidity figures of Pakistani citizens. In this situation, there should be a regular system of monitoring of health status of doctors and annual medical check up be made part of confidential report furnished by employees of Sindh Government. Moreover, health awareness and lifestyle change programmes be organized for doctors related to their own health and fitness like use of iodine salt and exercise. Treatment facilities for doctors be made free or highly subsidized in private sector hospitals and health screening and research programmes be started for doctors in Sindh.

\section{ACKNOWLEDGEMENT}

This data was possible to be collected by cooperation of Dr. Rafique Ahmed Kolachi, then Provincial HMIS Coordinator, Sindh and doctors from various districts, especially female doctors are thanked for furnishing data on questionnaire as well as Maulana Qudoos, an employee of Health department for mailing and logistic support.

\section{REFERENCES}

1. Government of Pakistan, Ministry of Health. HMIS Feed Back Report 2001, Islamabad. 2001.

2. Government of Pakistan. National Economic Survey. Islamabad. Ministry of Economic Affairs. 2003-2004: P. 61

3. Unaiza N, Sehar $H$ and Sobia A. Stress in women physicians of Pakistan. Pak J Med Sci. 2003; 19 (2): $89-94$.

4. Kay MP, Mitchell GK, Christopher B. Doctors do not adequately look after their own physical health. Med J Aust. 2004; 181(7): 368-70.

5. Chambers R. Health and lifestyle of general practitioners and teachers. Occup Med (Lond). 1992; 42: 69-78.

6. Nyman K. The health of general practitioners; A pilot survey. Aust Fam Physician. 1991; 20: 63745.

7. Richards JG. The health and health practice of doctors and their families. NZ Med J. 1999; 112 (1084): 96-9.

8. Firth $\mathrm{CJ}$. Doctors, their well being and their stress. It's time to be proactive about stress and prevent it. Br Med J. 2003; 326: 670-71.

9. Samkoff J, Hockenberry S, Simon LJ, et al. Mortality of young physicians in the United States.

10. Hashmi MJ. Disease burden and healthcare priorities. Available at: www.PrimaryCarePk.org, Accessed in April 2003.

11. Karim MS. Disease pattern, health services utilization and cost of treatment in Pakistan. J Pak Med Assoc. 1993;43(8):159-64.

12. Khan KS. Setting health care priorities in Pakistan. J Pak Med Assoc. 1995; 45(8): 222-7.

13. Hyder AA, Morrow RH. Applying burden of disease methods in developing countries: a case study from Pakistan. Am J Public Health. 2000;90 (8):1235-40.

AUTHOR AFFILIATION:
Dr. Hussain Bux Kolachi (Corresponding Author)
Associate Professor
Department of Community Medicine
Liaquat University of Medical and Health Sciences
Jamshoro, Sindh - Pakistan.
Email: kolachi83@hotmail.com
Prof. Ayoob Ali
Institute of Public Health
Lahore, Punjab - Pakistan.
Dr. Mansoor A. Khuwaja
Associate Professor, Department of Community Medicine
ISRA Univesity Hyderabad, Sindh - Pakistan.

